\title{
Non-Insulin Therapeutic Option in Management of Diabetes: Life Style Modification; Diet and Exercise
}

\author{
Udaya M. Kabadi \\ Broadlawns Medical Center, Des Moines and University of Iowa, Iowa City, USA \\ Email: ukabadi@gmail.com
}

How to cite this paper: Kabadi, U.M. (2021) Non-Insulin Therapeutic Option in Management of Diabetes: Life Style Modification; Diet and Exercise. Journal of Diabetes Mellitus, 11, 288-304.

https://doi.org/10.4236/jdm.2021.115023

Received: October 26, 2021

Accepted: November 14, 2021

Published: November 17, 2021

Copyright $\odot 2021$ by author(s) and Scientific Research Publishing Inc. This work is licensed under the Creative Commons Attribution International License (CC BY 4.0).

http://creativecommons.org/licenses/by/4.0/

\section{(c) (i) Open Access}

\begin{abstract}
Life style modifications involve guidance regarding dietary alterations and tailored physical activity. Diabetic diets have evolved with changing times. Prior to advent of insulin, caloric restriction and ketogenic diet prolonged the life expectancy to 1.9 to 2.3 years in subjects with type 1 diabetes. However, caloric restriction in obese subjects with diabetes has been recommended throughout the history. Since the availability of insulin, diets for diabetes have been repeatedly debated primarily regarding caloric contribution derived from the carbohydrate content. However, recommendations to avoid ingestion of refined sugar and saturated fats have remained consistent. Finally, diabetic diets are being formulated by nutritionists based on ethnicity, nationality, culture and eating habits of the individual. Caloric content is based on the patient's body build, weight, energy needs and physical activity and may be adjusted according to individual eating habits, type of insulin regimen, and metabolic derangements. The proportion of caloric sources (fat, carbohydrate, protein) may be altered depending on the presence of secondary disorders. Several small daily meals, including a bedtime snack, are advised. Diabetic diets are often cost-effective, contrary to common belief. Patients should be encouraged to exercise to achieve optimum metabolic control. Active patient participation in the management program is an essential component of therapy.
\end{abstract}

\section{Keywords}

Diabetic Diets, Carbohydrate Content, Caloric Counts and Distribution

\section{History of Diabetic Diet}

An appropriate diet is the cornerstone of diabetes management has been recog- 
nized for over 5000 years. Initial documentation of Dietary treatment of diabetes mellitus goes as far back as $3500 \mathrm{BC}$ in Egypt [1] [2]. Another specific diet for treatment of diabetes is credited to Sushruta and Charaka in the ancient literature in India more than 2000 years ago [1]. For a long time until relatively recently in the 18th century, John Rollo documented reduction in glycosuria with implementation of calorie restriction in some subjects with (probably type 2) diabetes [1]. In 1797, Rollo developed the first such diet, consisting of four meals: breakfast (1 1/2 pt of milk, $1 / 2$ pt of lime water, bread and butter), lunch (pudding of blood and suet), dinner (old, rancid meats), and supper (the same as breakfast) [1]. In 1870, Bouchardat had observed a reduction of glycosuria in diabetic patients who existed on starvation rations during the siege of Paris [3]. Thus, he confirmed Rollo's observation and recommended that diabetic patients eat small amounts of food, especially carbohydrate [3]. In more modern history, the importance of diet as a major treatment of diabetes was again emphasized by Frederick Madison Allen and Elliott Joslin in the early 20th century (1919) prior to discovery of insulin [1]. They demonstrated that lean subjects with diabetes (probably type 1) administered a low-calorie diet with nearly zero-carbohydrate content prevented deaths from ketoacidosis and extended survival for 1.3 to 2.9 years [1]. However, this approach provoked onset of various other medical disorders [3]. The introduction of insulin by Frederick Banting in 1922 afforded patients a new opportunity to practice flexibility in their eating patterns [3]. After diabetes was recognized to involve aberrations of glucose metabolism, nutrients other than carbohydrate were thought to be better utilized by the body. The diet for diabetics at the London Hospital in 1931 consisted of extremely high fat content (68\%), low carbohydrate (15\%) and protein (17\%) contents [1] [2]. A low-carbohydrate diet was advocated until only a few years ago. At present, variable carbohydrate content of diet according to various individual factors is encouraged. Further understanding of the influence of diet in diabetes management led the American Diabetes Association, in conjunction with the U.S. Public Health Service, to introduce the "exchange scheme" in the 1950s [4]. These recommendations provided guidelines for exchanging one food item of similar nutrition value especially a carbohydrate for another. Ongoing evaluation of the exchange scheme resulted in repeated revised guidelines by ADA in 1976, 1986, and again in 1995 [4]. On recent understanding of the concept of "glycemic index", the exchange schemes have been relegated in preference of other dietary recommendations [4] [5] [6]. A diet high in plant fiber was initially recommended by James Anderson [5]. This guidance was based on his own studies as continuation of the work of Denis Burkitt, Hugh Trowell and Price on dietary fiber [6] [7]. Therefore, in recent times, many nutritionists have shunned away of recommending the exchange scheme. Instead, they are likely to recommend a typical healthy diet: one high in fiber, with a variety of fruit and vegetables, and low in both sugar and fat, especially saturated fat [4]-[11].

Concurrent with dietary evolution, the role of physical activity (exercise) in 
management of diabetes was being established [8] [9] [10]. In response to this data, Nathan Pritikin opened a first fitness center in 1976 where patients participated in an ongoing programming of diet and exercise (the Pritikin Program). The diet recommended by the Pritkin program focused on high carbohydrate and fiber contents derived from fresh fruit, vegetables and whole grains. In 2005, the utility of the Pritkin program achieved a dramatic metabolic improvement in just three weeks amongst a group of subjects with diabetes or pre-diabetes with about half attaining remission [8] [9] [10] [11]. Finally with advent of information technology, mobile applications for managing diabetic patients' nutrition have become available [12].

The presently recommended diet by American Diabetes Association has evolved over centuries [13]. It excludes refined sugars, has a polyunsaturated fat/saturated fat ratio $>1: 1$, and includes limited intake of trans fats to protect against cardiovascular disease, the most frequent cause of death [14] [15] [16]. Ideal contribution of carbohydrates, fats and proteins to daily diet is variable according to ethnicity, age, gender and associated disorders. Meal plans should be tailored for individual subjects based on daily caloric intake and metabolic goals. Most frequently utilized meal pattern includes distribution of daily calories into 3 major meals and a bedtime snack (Table 1). However, a variety of eating patterns may be considered dependent on habits, occupations and shifts of work etc. with a major objective of achieving uniform diurnal glycemia in the target range (70 $180 \mathrm{mg} / \mathrm{dl}$ ) in subjects with diabetes and delay onset of diabetes in individuals with pre-diabetes [13]. Most diabetic diets also recommend adequate fiber intake to delay food absorption and induce favorable alterations in gut morphology [17]-[27]. However the quantity of fiber required to provide these benefits is almost five times the amount in a normal diet, and is likely to cause abdominal distention, diarrhea, flatulence, and mineral losses [24] [28] [29]. Since the tolerable and acceptable fiber content is unknown in an individual subject, low fiber intake should be initiated and then increased gradually, allowing for developing tolerance to an intake of almost $45 \mathrm{~g}$ without altered nutrient absorption [13] [22] [29] [30].

\section{Objectives}

The goals of nutritional therapy in diabetes are to attain and maintain ideal body weight in adults, achieve normal growth rate in children, attain and maintain desirable glycemic control to avoid acute complications and prevent or delay long-term complications while providing optimum nutrition. Lifelong compliance and adherence on the part of the patient are crucial and therefore require appropriate long-term plan with recurrent education utilizing several motivational techniques (Table 2).

A lifelong nutritional therapy in patients with diabetes involves the following goals and principles:

1) Attainment and maintenance of ideal body weight through weight reduction in obese patients with type 2 and weight gain with type 1 diabetes (Table 3 ). 
2) A team approach to therapy through emphasis on the involvement of the patient and his or her family and recurrent evaluation and support by the health care team.

3) Individualized meal planning based on associated disorders, degree of activity, and eating habits.

Table 1. Preferred general distribution of calories in meal plans for most subjects with diabetes*.

\begin{tabular}{cc}
\hline Proportion of daily caloric intake by meal & \\
\hline $2 / 10$ & Breakfast \\
$3 / 10$ & Lunch \\
$4 / 10$ & Supper \\
$1 / 10$ & Bedtime Snack $^{\dagger}$ \\
\hline
\end{tabular}

*Should be individualized according to each patients' degree of activity, job schedule, etc. 'Important in preventing nocturnal hypoglycemia.

Table 2. Motivational techniques for encouraging patient compliance to diabetic diet [31] [32] [33].

1. Stimulate patient awareness of and interest in diet, nutrition, and diabetes by explaining, in simple terminology, relationship between disease control and complications, rationale of treatment, and impact of social and environmental factors.

2. Develop good rapport and satisfactory relationship with patient. Be empathetic and compassionate but firm.

3. Make patient aware of goals of therapy. Allow patient to set only achievable goals, since setting of unrealistic goals inevitably leads to failure and discouragement. Encourage patient to recover from binges and setbacks and to try again. Ascertain patient's interest in order to provide new motivation and encouragement and set new goals. Ask questions that stimulate curiosity and general discussion; avoid questions that may be answered with "yes" or "no".

4. Continually encourage patient to assume responsibility for himself or herself. Refute excuses for noncompliance.

5. Encourage patient to record daily food intake and weekly weight measurement. Evaluate records with patient.
6. Encourage patient to become interested in daily, consistent exercise, new activities, and activities involving other people. Convince patient to deemphasize events revolving around food.

7. Encourage patient to deal with emotions d (guilt, boredom, anxiety, anger, depression, self-pity, happiness) in ways other than excessive eating or binging.

8. Promote use of variety of foods and recipes to prevent boredom with diet.

9. Encourage patient to increase intake of bulk and fiber in diet, which may deter snacking. Incorporate raw foods, clear hot soups, and low-calorie beverages into diet to increase feeling of satiety. Encourage patient to eat slowly.

10. Institute gradual changes in diet plan to improve adaptability in noncompliant patient.

11. Institute behavior modification if necessary. 
Table 3. Methods for calculation of ideal body weight.

\section{Adults:}

1. Simple method*

Men: $47.7 \mathrm{~kg}(106 \mathrm{lb})$ for first $150 \mathrm{~cm}(5 \mathrm{ft})$ of height. Add $2.7 \mathrm{~kg}(6 \mathrm{lb})$ for each additional $2.5 \mathrm{~cm}$ (1 in.). (Variance of $10 \%$ allowed for large or small frame)

Women: $45 \mathrm{~kg}(100 \mathrm{lb})$ for first $150 \mathrm{~cm}(5 \mathrm{ft})$ of height. Add $2.25 \mathrm{~kg}(5 \mathrm{lb})$ for each additional $2.5 \mathrm{~cm}$ (1 in.)

2. Broca's Index ${ }^{\dagger}$

Height in $\mathrm{cm}-100=$ optimum body weight in $\mathrm{kg}$

3. Nomogram $^{\ddagger}$

\section{Children:}

Growth chart (Wetzel, Iowa or Stuart)*: Height and weight must be charted every 3 mo on continuum. Most children remain in same growth percentile throughout childhood if adequate calories and appropriate insulin therapy provided.

*Adapted from Danowski TS, ed. Diabetes mellitus: diagnosis and treatment. Vol 1. New York: Am Diabetes Assn, 1964: 73-78 [34]; ${ }^{\dagger}+$ Adapted from Bray GA. Definition, measurement, and classification of the syndromes of obesity. Int J Obes 1978: 2 (2): 99-112 [35]; ${ }^{\ddagger}$ From Boothby WM, Berkson J, Dunn HL. Studies of the energy of normal individuals: a standard for basal metabolism, with a nomogram for clinical application. AM J Physiol 1936: 116 (2): 468-484 [36].

4) Careful balance between nutrient intake, energy expenditure, and the dose and timing of the drugs (i.e. oral agents, insulin)

5) Goal-oriented progress based on recurrent counseling with revision to new goals, with adjustment of caloric intake based on weight loss in type 1 and weight gain in type 2 (Table 4).

6) Behavior modification must include long term planning and must be persistent, repetitive and must be emphasized at each clinic visit Motivational techniques may be helpful to encourage patient compliance (Table 2). Institute gradual changes in diet plan to improve adaptability on the part of patients.

\section{Implementation}

Diabetes therapy is often determined by the type of diabetes mellitus [13]. For patients with both type 1 and type 2, meal planning must include guidelines for both food choices and caloric intake. In patients with type 1, daily caloric intake may be unrestricted at diagnosis as most of the patients are young and experience weight loss prior to diagnosis. The plan must emphasize timing and consistency of meals with appropriate diet composition (e.g. increased protein intake during adolescence, adjustment of calories for exercise and other physical activities, pubertal status, pregnancy and lactation needs, and growth assessment.

The major goal of nutritional therapy in subjects with type 2 and obesity is to attain and maintain ideal body weight. Total caloric content of the diet is more crucial than the constituents for promoting weight loss. The number of fat cells 
Table 4. Methods for estimating appropriate caloric level for achievement and maintenance of ideal body weight.

\section{For adults:}

1) Begin with 22 calories/kg (10 calories/lb) of ideal body weight to determine caloric level for resting in bed.

2) Increase resting caloric requirement by percentage to allow for daily activity level: minimal ambulation, $20 \%$ - 25\%; sedentary job, $40 \%-50 \%$; moderate activity $70 \%-75 \%$; manual labor (e.g., construction work), $75 \%-100 \%$.

3) a. Add (subtract) percentage of daily requirement corresponding to percentage underweight (overweight).

b. Add (subtract) 500 calories for weekly weight gain (loss) of $1 \mathrm{lb}$. Add 300 calories daily for pregnant and 500 calories daily for lactating women.

4) Supplement diet of less than 1200 calories with multiple vitamin to meet daily vitamin requirements.

\section{For children:}

Begin with 1000 calories for first year of life; add 100 calories for each succeeding year.

may increase permanently during a period of rapid weight gain [37]. Starvation diets should therefore be discouraged, as most patients tend to overeat and regain weight after the starvation period. The presence of childhood obesity also poses a problem because of an increased number of fat cells formed during periods of rapid growth, particularly during infancy [38]. Despite an adequate compliance, these patients have difficulty achieving the same weight loss as patients who become obese as adults. Therefore, gradual and consistent weight loss is the primary focus. The attainment of ideal body weight and the time factor are secondary since the prognosis is poor and the success rate is minimal in patients who go through cycles of rapid weight gain and loss because of intermittent noncompliance with diet. Weight loss is not always steady and predictable in most patients. It may reach a plateau if total calories are not further reduced because of the body's adaptation to the initial caloric intake and a $15 \%$ to $30 \%$ decrease in metabolism induced by altered hormonal milieu [39] [40] [41] [42]. Goals must therefore be continually revised. The patient must regard the meal plan as a permanent change in lifestyle [43].

A weight-reduction diet must include adequate intake of protein and carbohydrate to spare protein for anabolic purposes. Frequency of meals is extremely important. Food consumption itself stimulates metabolism (dietary thermogenesis), which is decreased in obese persons [44] [45] [46]. Lack of food intake for several hours may result in late reactive hypoglycemia in patients with type 2 diabetes. For these patients, three or four small meals a day are better than one large meal. Generally, ingestion of one large daily meal leads to uncontrolled appetite during the rest of the day and encourages binge eating. Also, calories are used more efficiently and cholesterol levels and degree of glucose intolerance improve when three to six meals are consumed rather than one large meal [47]. 
Some persons who take in small feedings may eventually adapt to a low caloric intake, making further weight reduction difficult. Therefore, close follow-up of patients is necessary so that the diet plan can be adjusted. Most studies [13] [47]-[53] advocate a distribution of two tenths to four tenths of calories at each meal and one tenth for each snack especially at bedtime (Table 1). Bedtime snack is helpful in reducing these frequency of nocturnal hypoglycemia, which may go unrecognized in some patients. In other patients, hypoglycemia may manifest as nightmares or night sweat, often followed by headache on awakening due to rebound morning hyperglycemia (Somogyi effect).

Patients' dietary habits must be recognized and respected as they are deeply ingrained. Therefore, modification of diet requires intensive, persistent and recurrent counseling in order to develop new eating habits. Patients must realize that they and their families are the major active participants in the management team, since family support enhances patient attitude and compliance. Frequent follow-up visits with management team (e.g. physician, Diabetes educator, psychologist, dietitian) are the crux of achieving a successful outcome. Diabetic diets have the reputation of being expensive; though without much evidence [13] [54]. Most patients are able to afford the diet, since it generally consists of the same types of food consumed by other family members, with some modifications. Low-cost sources of protein with high nutrient density (e.g. legumes, peanut butter, nonfat dry milk, fish) may be suggested, as may iron-fortified cereals, which provide economical sources of iron and minerals. Use of home-grown foods can also help reduce costs. Family members must be involved in diabetic treatment, and the development of a meal plan should be discussed with them. Support from family members has a beneficial effect on the patient's attitude and compliance.

\section{Controversies}

The concept of glycemic index was introduced by in the 1980 [55]. This term relates to the degree of post prandial glycemia occurring following ingestion of individual food items (e.g., rice, bread, ice cream etc.) in comparison with glycemia of the same quantity of glucose. Similar studies were conducted by Dr. J. C. Patel and his colleagues in India in the 1950s comparing the effect of 'ragi, roti or bhakri' (bread) with rice and other foods [56] [57]. However, the influence of ingestion of carbohydrates based on glycemic index on glycemic control is inconsistent [58] [59] [60] [61] [62]. Moreover, the concept is less than practical and confusing to most patients.

Debate regarding the carbohydrate content continues. Early epidemiological studies provide circumstantial evidence that diets high in complex carbohydrate and low in fat protect against heart disease [50] [51] [63] [64]. Since atherosclerotic lesions account for $75 \%$ to $85 \%$ of deaths of diabetics in the United States, the recommendation of low-fat diet appears to be prudent [65] [66] [67]. However, recent studies have demonstrated that diets with low carbohydrate, high fat contents "ketogenic diets" may offer greater benefits in terms of glycemic con- 
trol as well as other metabolic indices including cardiovascular risk markers as well as outcomes [68] [69] [70] [71] [72]. However, low-carbohydrate eating plans generally indicate challenges with long-term sustainability [72]. Finally, majority of subjects with diabetes in USA consume diets with carbohydrate content close to $50 \%$, similar to most of the population. Long term success rates despite intense efforts to alter ingrained eating habits are dismal as people revert to their usual distribution of calories among food groups [72]. Therefore, individualizations of the meal plans based on personal characteristics is likely to the most effective approaching achieving consistency and long-term maintenance [13] [73] [74].

Another controversial aspect of the diet is the inclusion of simple refined sugars. Several studies have shown that without any additional intervention the amount of simple sugar in meal may not worsen postprandial glycemia in most patients with type 2 diabetes [75] [76] [77]. Even in patients with type 1, ingestion of refined sugar may not exacerbate postprandial glycemia if the pre-prandial rapid acting insulin dose is adjusted with a correction factor [78] [79]. We believe that postprandial glycemia may actually improve in type 2 patients with optimal metabolic control, since their insulin secretory pattern is normalized, and the simple sugar is the best stimulus for insulin secretion [76]. Foods containing simple sugars (e.g. candy) are discouraged because of the possibility of their causing a precipitous rise in blood glucose, even though some recent reports have suggested that simple sugars may not induce hyperglycemia [75] [76] [77] [78] [79]. The long-term effects of simple sugars in a diabetic diet are not known.

Subjects with diabetes accustomed to consuming sugar containing food products, non-nutrient sweeteners may be recommended as substitutes though in moderation [13]. However, most organizations discourage consumption of non-nutritive sweeteners. Flavored water products are encouraged instead.

Many diabetic patients inquire about alcohol consumption. There is no firm evidence that small amounts of alcohol are harmful. Patient must be advised regarding the importance of food consumption with alcohol intake in order to avoid onset of hypoglycemia which is often sustained, especially while receiving insulin. Therefore patients must be advised to monitor blood sugar frequently after alcohol consumption to avoid hypoglycemia. In patients choosing to drink, the guidelines established for non-diabetic subjects are recommended. The guidelines include a single drink per day for women and no more than two drinks per day for men. One drink equals $12-\mathrm{oz}$ beer, 5 -oz of wine, or $1.5 \mathrm{oz}$ of distilled spirits. However, a cautious approach may help prevent addiction.

Over the counter supplements such as selenium, vanadium, turmeric, cinnamon etc. as well as are not recommended by ADA due to lack of quality evidence [13].

\section{Diet Recommendations (Practical Consideration)}

Although guidelines for the formulation of diabetic diet are established by vari- 
ous organizations, individualized modifications are essential to adapt to special patient needs e.g. caloric intake based on body weight, carbohydrate content, sodium restriction for hypertension, increased protein for trauma and stress, restricted protein for liver and renal diseases etc.

Since carbohydrate responsive dyslipidemia with elevation of triglycerides occurs in some patients, the carbohydrate content of the diet may need to be reduced substantially. Caloric excess and obesity contribute to hypertriglyceridemia as well. Therefore, caloric restriction and a relatively low carbohydrate intake are therapeutic to attain desirable metabolic goals in these patients.

A detailed diet history, must include the preceding data regarding patient's preferences about average daily caloric intake, typical distribution of calories into food contents as well as number of daily meals, nutrients and nutritional literacy. The major objective of nutritional intervention is to attain and maintain ideal body weight. The caring team must discuss this goal with the patient and next of kin. Inquiring of the patient's impression of the healthy body weight may arouse patient's interest in understanding the role of diet in management as well as stimulate patient motivation and participation rendering better compliance. In contrast, telling the patient about goal of the team unilaterally may induce resentment. Moreover, the information about the patient's minimum, maximum, and usual body weight during life may help decide the weight goal as well as the period to attain the goal. Ideal body weight should be a range rather than a single number. Gradual reduction is more appealing to the patient than rapid weight loss, to the patient, a goal of weight loss $36 \mathrm{~kg}(80 \mathrm{lb})$ seems overwhelming and thus discouraging, while a goal of $2.25 \mathrm{~kg}(5 \mathrm{lb})$ per month appears reasonable and attainable. Achieving the ideal body weight must be the major goal; the time factor is a distant second. Reduced daily caloric intake is the main contributor to promoting weight loss, not the food constituents (Table 4).

As therapy progresses, goals must be altered. The patient is encouraged to regard the meal plan as a permanent change in life-style. Since dietary habits are deeply ingrained, modification of diet involves intensive long-term counseling.

Bariatric procedure may assist achieving weight loss [80] [81] [82] [83]. However, all subjects undergoing the procedure must be alerted and educated regarding consequences of the procedure. Moreover, the ongoing education must include the discussion of the approaches to prevent or manage the side effects.

In addition to attaining and maintaining ideal body weight, the patient needs to develop consistent eating habits that include a nutritionally adequate meal plan. The keys to patient compliance are an individualized diet plan and ongoing active patient involvement.

\section{Role of Exercise}

Diabetic patients should be encouraged to exercise when feasible. Exercise enhances insulin sensitivity by facilitating the binding of insulin to its receptor sites and activating post receptor mechanisms [84] [85] [86] [87] [88]. Exercise also 
promotes utilization of stored fats and lowers serum lipid levels. Exercise improves muscle tone, increases endurance, and promotes a feeling of well-being by decreasing boredom and depression, both of which can lead to overeating and poor appetite control. Exercise, in conjunction with a weight reduction diet, will often spare lean body mass without significantly affecting weight loss [84] [85] [86].

The type, the strenuousness and the duration of exercise must be tailored for individual patient based on cardiac status and severity of neuropathy and vasculopathy. The simple, convenient and affordable exercise is "brisk walking" at a pace of about 100 steps a minute for 30 minutes [89]-[95]. Upper body and arm exercise can be performed by almost everyone including patients with neuropathy. Timing of exercise is extremely important as well. The most opportune time for exercise is the period with highest circulating insulin levels since exercise enhances insulin sensitivity. Therefore the most effective time for exercise in subjects with type 2 diabetes is $1-2$ hours post meal and at the time of the peak insulin levels attained following exogenous insulin administration.

Patients with type 1 diabetes should be especially cautious while performing strenuous exercise, as it may induce hypoglycemia. The patient can avoid hypoglycemic episodes by increasing food intake (Table 5) or decreasing insulin dosage before beginning exercise.

Hypoglycemia usually does not occur during or immediately following exercise because of simultaneously ongoing hepatic glucose production induced by exercise stimulated prompt secretion of counter regulatory hormones. Hypoglycemia can often be prevented or managed by patients and their family members who have been educated to recognize its symptoms. The usual means of control is ingestion of a rapidly absorbable carbohydrate, such as sugar, fruit juice, or regular (non-diet) diet soda pop. Foods with a high fat content (e.g. candy bars, caramels) are absorbed slowly and are not effective. After taking $10 \mathrm{gm}$ of simple carbohydrate, the patient should wait ten minutes. If symptoms persist, the patient should repeat this process. Patients should keep in mind that they may misjudge certain symptoms as a hypoglycemic reaction and hence may treat them without documenting low blood glucose. This action could be detrimental to overall control of diabetes.

Table 5. Guidelines for increasing food intake to allow for extra activity in diabetics on insulin therapy.

\begin{tabular}{|c|}
\hline ) \\
\hline $\begin{array}{l}\text { Moderate activity } \\
\text { (e.g., tennis, cycling, jogging, swimming) } \\
10-15\end{array}$ \\
\hline $\begin{array}{l}\text { Strenuous activity } \\
\text { (e.g., shoveling snow, ice hockey, football) } \\
30-50\end{array}$ \\
\hline
\end{tabular}


In summary, life style modification including appropriate advice regarding nutrition and physical activity remains a foundation of the therapeutic strategy in management of diabetes.

\section{Conflicts of Interest}

The author declares no conflicts of interest regarding the publication of this paper.

\section{References}

[1] Scaramuzza, A.E., Bosettie, A., Macedoni, M. and Ferrari, M. (2016) Nutritional Aspectes of Type 1 Diabetes: We Need to Keep Struggling against Paleolithic Diet (How Research Helps Us to Do the Right Thing). In: Scaramuzza, A.E., de Beaufort, C. and Hanas, R., Eds., Research into Childhood-Onset Diabetes. From Study Design to Improved Management, Springer, Berlin, 91. https://doi.org/10.1007/978-3-319-40242-0_8

[2] Porter, E. (2012) History of Diabetes. Healthline Media, San Francisco.

[3] Roberts, J. (2015) Sickening Sweet. Distillations, 1, 12-15.

[4] Peterson, A.R. and Chalmers, K.H. (1999) 16 Myths of a Diabetic Diet. American Diabetes Association, Alexandria, 85.

[5] Anderson, J.W. and Ward, K. (1979) High-Carbohydrate, High-Fiber Diets for Insulin-Treated Men with Diabetes Mellitus. The American Journal of Clinical Nutrition, 32, 2312-2321. https://doi.org/10.1093/ajcn/32.11.2312

[6] Trowell, H.C. and Burkett, D.P. (1981) Western Diseases: Their Emergence and Prevention. Harvard University Press, Cambridge, 13-16.

[7] Murray, M. and Pizzorno, J. (1990) Encyclopaedia of Natural Medicine. Littlebrown and Company, London.

[8] Booth, F.W. and Chakravarthy, M.V. (2006) Physical Activity and Dietary Intervention for Chronic Diseases: A Quick Fix after All? Journal of Applied Physiology, 100, 1439-1440. https://doi.org/10.1152/japplphysiol.01586.2005

[9] Roberts, C.K., Won, D., Pruthi, S., Kurtovic, S., Sindhu, R.K., Vaziri, N.D. and Barnard, R.J. (2006) Effect of a Short-Term Diet and Exercise Intervention on Oxidative Stress, Inflammation, MMP-9, and Monocyte Chemotactic Activity in Men with Metabolic Syndrome Factors. Journal of Applied Physiology, 100, 1657-1665. https://doi.org/10.1152/japplphysiol.01292.2005

[10] Roberts, C.K. and Barnard, R.J. (2005) Effects of Exercise and Diet on Chronic Disease. Journal of Applied Physiology, 98, 3-30. https://doi.org/10.1152/japplphysiol.00852.2004

[11] Bhattacharya, S. (2006) Three-Week Diet Curbs Diabetes. New Scientist.

[12] Norouzi, S., Kamel, G.A., Sistani, S., Banazadeh, V., Keykhaei, F., Zareishargh, P., Amiri, F., Nematy, M. and Etminani, K. (2018) A Mobile Application for Managing Diabetic Patients' Nutrition: A Food Recommender System. Archives of Iranian Medicine, 21, 466-472.

[13] American Diabetes Association (2021) Facilitating Behavior Change and Well-Being to Improve Health Outcomes: Standards of Medical Care in Diabetes-2021. Diabetes Care, 44, S53-S72. https://doi.org/10.2337/dc21-S005

[14] Gerstein, H.C. (2015) Diabetes: Dysglycaemia as a Cause of Cardiovascular Outcomes. Nature Reviews Endocrinology, 11, 508-510. 
https://doi.org/10.1038/nrendo.2015.118

[15] Ahmadizar, F., Wang, K., Aribas, E., Fani, L., Heshmatollah, A., Ikram, M.K. and Kavousi, M. (2021) Impaired Fasting Glucose, Type 2 Diabetes Mellitus, and Lifetime Risk of Cardiovascular Disease among Women and Men: The Rotterdam Study. BMJ Open Diabetes Research \& Care, 9, e002406.

https://doi.org/10.1136/bmjdrc-2021-002406

[16] Mosenzon, O., Alguwaihes, A., Leon, J.L.A., Bayram, F., Darmon, P., Davis, T.M.E., Dieuzeide, G., Eriksen, K.T., Hong, T., Kaltoft, M.S., Lengyel, C., Rhee, N.A., Russo, G.T., Shirabe, S., Urbancova, K., Vencio, S. and CAPTURE Study Investigators (2021) CAPTURE: A Multinational, Cross-Sectional Study of Cardiovascular Disease Prevalence in Adults with Type 2 Diabetes across 13 Countries. Cardiovascular Diabetology, 20, 154. https://doi.org/10.1186/s12933-021-01344-0

[17] Anderson, J.W. and Ward, K. (1978) Long-Term Effects of High Carbohydrate, High-Fiber Diets on Glucose and Lipid Metabolism: A Preliminary Report of Patients with Diabetes. Diabetes Care, 1, 77-82. https://doi.org/10.2337/diacare.1.2.77

[18] Miranda, D.M. and Horowitz, D.L. (1979) High-Fiber Diets in the Treatment of Diabetes Mellitus. Annals of Internal Medicine, 88, 482-486.

https://doi.org/10.7326/0003-4819-88-4-482

[19] Rivellese, A., Riccardi, G., Giacco, A., et al. (1980) Effect of Dietary Fiber on Glucose Control and Serum Lipoproteins in Diabetic Patients. The Lancet, 2, 447-450. https://doi.org/10.1016/S0140-6736(80)91886-3

[20] Jenkins, D., Wolever, T., Bacon, S., et al. (1980) Diabetic Diets: High Carbohydrate Combined with High Fiber. The American Journal of Clinical Nutrition, 33, 1729-1733. https://doi.org/10.1093/ajen/33.8.1729

[21] Simpson, H.C., Simpson, R.W., Lousley, S., et al. (1981) A High-Carbohydrate Leguminous Fibre Diet Improves All Aspects of Diabetic Control. The Lancet, 1, 2-5. https://doi.org/10.1016/S0140-6736(81)90112-4

[22] Chandalia, M., Garg, A., Lutjohann, D., von Bergmann, K., Grundy, S.M. and Brinkley, L.J. (2000) Beneficial Effects of High Dietary Fiber Intake in Patients with Type 2 Diabetes Mellitus. The New England Journal of Medicine, 342, 1392-1398. https://doi.org/10.1056/NEJM200005113421903

[23] Simpson, H.L. and Campbell, B.J. (2015) Review Article: Dietary Fibre-Microbiota Interactions. Alimentary Pharmacology \& Therapeutics, 42, 158-179. https://doi.org/10.1111/apt.13248

[24] Reynolds, A.N., Akerman, A.P. and Mann, J. (2020) Dietary Fibre and Whole Grains in Diabetes Management: Systematic Review and Meta-Analyses. PLOS Medicine, 17, e1003053. https://doi.org/10.1371/journal.pmed.1003053

[25] Wilson, A.S., Koller, K.R., Ramaboli, M.C., Nesengani, L.T., Ocvirk, S., Chen, C., Flanagan, C.A., Sapp, F.R., Merritt, Z.T., Bhatti, F., Thomas, T.K. and O’Keefe, S.J.D. (2020) Diet and the Human Gut Microbiome: An International Review. Digestive Diseases and Sciences, 65, 723-740. https://doi.org/10.1007/s10620-020-06112-w

[26] Makki, K., Deehan, E.C., Walter, J. and Bäckhed, F. (2018) The Impact of Dietary Fiber on Gut Microbiota in Host Health and Disease. Cell Host \& Microbe, 23, 705-715. https://doi.org/10.1016/j.chom.2018.05.012

[27] Ojo, O., Feng, Q.Q., Ojo, O.O. and Wang, X.H. (2020) The Role of Dietary Fibre in Modulating Gut Microbiota Dysbiosis in Patients with Type 2 Diabetes: A Systematic Review and Meta-Analysis of Randomised Controlled Trials. Nutrients, 12, 3239. https://doi.org/10.3390/nu12113239

[28] Peng, A.W., Juraschek, S.P., Appel, L.J., Miller, E.R. and Mueller, N.T. (2019) Effects 
of the DASH Diet and Sodium Intake on Bloating: Results from the DASH-Sodium Trial. American Journal of Gastroenterology, 114, 1109-1115. https://doi.org/10.14309/ajg.0000000000000283

[29] Anderson, J.W., Ferguson, S.K., Karounos, D., et al. (1980) Mineral and Vitamin Status of High Fiber Diets: Long-Term Studies of Diabetic Patients. Diabetes Care, 3, 38-40. https://doi.org/10.2337/diacare.3.1.38

[30] Torre, M., Rodriguez, A.R. and Saura-Calixto, F. (1991) Effects of Dietary Fiber and Phytic Acid on Mineral Availability. Critical Reviews in Food Science and Nutrition, 30, 1-22. https://doi.org/10.1080/10408399109527539

[31] Young-Hyman, D., de Groot, M., Hill-Briggs, F., Gonzalez, J.S., Hood, K. and Peyrot, M. (2016) Psychosocial Care for People with Diabetes: A Position Statement of the American Diabetes Association. Diabetes Care, 39, 2126-2140. https://doi.org/10.2337/dc16-2053

[32] Powers, M.A., Bardsley, J.K., Cypress, M., et al. (2020) Diabetes Self-Management Education and Support in Adults with Type 2 Diabetes: A Consensus Report of the American Diabetes Association, the Association of Diabetes Care \& Education Specialists, the Academy of Nutrition and Dietetics, the American Academy of Family Physicians, the American Academy of PAs, the American Association of Nurse Practitioners, and the American Pharmacists Association. Diabetes Care, 43, 1636-1649. https://doi.org/10.2337/dci20-0023

[33] Kabadi, U.M. (1986) Nutritional Therapy in Diabetes: Rationale and Recommendations. Postgraduate Medicine, 79, 145-156.

https://doi.org/10.1080/00325481.1986.11699428

[34] Danowski, T.S. (1964) Diabetes Mellitus: Diagnosis and Treatment. Vol. 1, American Diabetes Association, New York, 73-78.

[35] Bray, G.A. (1978) Definition, Measurement, and Classification of the Syndromes of Obesity. International Journal of Obesity, 2, 99-112.

[36] Boothby, W.M., Berkson, J. and Dunn, H.L. (1936) Studies of the Energy of Normal Individuals: A Standard for Basal Metabolism, with a Nomogram for Clinical Application. American Journal of Physiology, 116, 468-484. https://doi.org/10.1152/ajplegacy.1936.116.2.468

[37] Björntorp, P., Carlgren, G., Isaksson, B., et al. (1975) Effect of an Energy-Reduced Dietary Regimen in Relation to Adipose Tissue Cellularity in Obese Women. The American Journal of Clinical Nutrition, 28, 445-452.

https://doi.org/10.1093/ajcn/28.5.445

[38] Hirsh, J. and Knittle, J.L. (1970) Cellularity of Obese and Non-Obese Human Adipose Tissue. Federation Proceedings, 29, 1516-1521.

[39] Apfelbaum, M., Bostsarron, J. and Lacatis, D. (1971) Effect of Calorie Restriction ad Excessive Caloric Intake on Energy Expenditure. The American Journal of Clinical Nutrition, 24, 1405-1409. https://doi.org/10.1093/ajcn/24.12.1405

[40] Somogyi, V., Gyorffy, A., Scalise, T.J., Kiss, D.S., Goszleth, G., Bartha, T. and Frenyo, V.L. (2011) Endocrine Factors in the Hypothalamic Regulation of Food Intake in Females: A Review of the Physiological Roles and Interactions of Ghrelin, Leptin, Thyroid Hormones, Oestrogen and Insulin. Nutrition Research Reviews, 24, 132-154. https://doi.org/10.1017/S0954422411000035

[41] Zhao, X., Han, Q., Gang, X., Lv, Y., Liu, Y., Sun, C. and Wang, G. (2017) The Role of Gut Hormones in Diet-Induced Weight Change: A Systematic Review. Hormone and Metabolic Research, 49, 816-825. https://doi.org/10.1055/s-0043-115646

[42] Näätänen, M., Kolehmainen, M., Laaksonen, D.E., Herzig, K.-H., Poutanen, K. and 
Karhunen, L. (2021) Post-Weight Loss Changes in Fasting Appetite- and Energy Balance-Related Hormone Concentrations and the Effect of the Macronutrient Content of a Weight Maintenance Diet: A Randomised Controlled Trial. European Journal of Nutrition, 60, 2603-2616. https://doi.org/10.1007/s00394-020-02438-3

[43] Bowen, M.E., Cavanaugh, K.L., Wolff, K., et al. (2016) The Diabetes Nutrition Education Study Randomized Controlled Trial: A Comparative Effectiveness Study of Approaches to Nutrition in Diabetes Self-Management Education. Patient Education and Counseling, 99, 1368-1376. https://doi.org/10.1016/j.pec.2016.03.017

[44] Bosy-Westphal, A. (2013) Adaptive Thermogenesis with Weight Loss in Humans. Obesity (Silver Spring), 21, 218-228. https://doi.org/10.1002/oby.20027

[45] Sakamoto, T., Takahashi, N., Goto, T. and Kawada, T. (2014) Dietary Factors Evoke Thermogenesis in Adipose Tissues. Obesity Research \& Clinical Practice, 8, e533-e539. https://doi.org/10.1016/j.orcp.2013.12.002

[46] Calcagno, M., Kahleova, H., Alwarith, J. and Nora, N. (2019) The Thermic Effect of Food: A Review. Journal of the American College of Nutrition, 38, 547-551. https://doi.org/10.1080/07315724.2018.1552544

[47] Weinsier, R.L., Seeman, A., Herrera, M.G., et al. (1974) Diet Therapy of Diabetes: Description of a Successful Methodologic Approach to Gaining Diet Adherence. Diabetes, 23, 669-673. https://doi.org/10.2337/diab.23.8.669

[48] Mann, J.I. (1980) Diet and Diabetes. Diabetologia, 18, 89-95. https://doi.org/10.1007/BF00290483

[49] Vinik, A.I. and Wing, R.R. (1992) The Good, the Bad, and the Ugly in Diabetic Diets. Endocrinology \& Metabolism Clinics of North America, 21, 237-239. https://doi.org/10.1016/S0889-8529(18)30217-2

[50] Thom, S.L. (1993) Nutritional Management of Diabetes. Nursing Clinics of North America, 28, 97-112.

[51] Quinn, S. (1993) Diabetes and Diet. We Are Still Learning. Medical Clinics of North America, 77, 773-782. https://doi.org/10.1016/S0025-7125(16)30223-1

[52] Kadowaki, T., Haneda, M., Ito, H., Sasaki, K., Hiraide, S., Matsukawa, M. and Ueno, M. (2018) Relationship of Eating Patterns and Metabolic Parameters, and Teneligliptin Treatment: Interim Results from Post-Marketing Surveillance in Japanese Type 2 Diabetes Patients. Advances in Therapy, 35, 817-831. https://doi.org/10.1007/s12325-018-0704-2

[53] Kempf, K., Röhling, M., Niedermeier, K., Gärtner, B. and Martin, S. (2018) Individualized Meal Replacement Therapy Improves Clinically Relevant Long-Term Glycemic Control in Poorly Controlled Type 2 Diabetes Patients. Nutrients, 10, 1022. https://doi.org/10.3390/nu10081022

[54] Chrysostomou, S., Koutsampelas, C. andreou, S.N. and Pittas, C. (2020) The Purchase of the Diabetic Healthy Food Basket in Cyprus Results in Cost Savings: Is It Affordable among the Low-Income Population? Public Health Nutrition, 23, 3409-3416. https://doi.org/10.1017/S1368980020001184

[55] Jenkins, D.J.A., Wolever, T.M.S., Jenkins, A.L., et al. (1983) The Glycemic Index of Foods Tested in Diabetic Patients: A New Basis for Carbohydrate Exchanges Favoring the Use of Legumes. Diabetologia, 24, 257-264. https://doi.org/10.1007/BF00282710

[56] Patel, J.C., Dhirawani, M.K. and Darne, R.D. (1968) Ragi in the Management of Diabetes Mellitus. Indian Journal of Medical Sciences, 22, 28-29.

[57] Patel, J.C., Metha, A.B., Dhirawani, M.K., Juthani, V.J. and Aiyer, L. (1969) High 
Carbohydrate Diet in the Treatment of Diabetes Mellitus. Diabetologia, 5, 243-247. https://doi.org/10.1007/BF01212092

[58] Ma, Y.S., Olendzki, B.C., Merriam, P.A., Chiriboga, D.E., Culver, A.L., Li, W.J., Hébert, J.R., Ockene, I.S., Griffith, J.A. and Pagoto, S.L. (2008) A Randomized Clinical Trial Comparing Low-Glycemic Index versus ADA Dietary Education among Individuals with Type 2 Diabetes. Nutrition, 24, 45-56. https://doi.org/10.1016/j.nut.2007.10.008

[59] Thomas, D. and Elliott, E.J. (2009) Low Glycaemic Index, or Low Glycaemic Load, Diets for Diabetes Mellitus. Cochrane Database of Systematic Reviews, 1, CD006296. https://doi.org/10.1002/14651858.CD006296.pub2

[60] Wheeler, M.L., Dunbar, S.A., Jaacks, L.M., et al. (2012) Macronutrients, Food Groups, and Eating Patterns in the Management of Diabetes: A Systematic Review of the Literature, 2010. Diabetes Care, 35, 434-445. https://doi.org/10.2337/dc11-2216

[61] Vega-López, S., Venn, B.J. and Slavin, J.L. (2018) Relevance of the Glycemic Index and Glycemic Load for Body Weight, Diabetes, and Cardiovascular Disease. $\mathrm{Nu}$ trients, 10, E1361. https://doi.org/10.3390/nu10101361

[62] Zafar, M.I., Mills, K.E., Zheng, J., et al. (2019) Low-Glycemic Index Diets as an Intervention for Diabetes: A Systematic Review and Meta-Analysis. The American Journal of Clinical Nutrition, 110, 891-902. https://doi.org/10.1093/ajcn/nqz149

[63] Kiehm, T.G. anderson, J.W. and Ward, K. (1976) Beneficial Effects of a High Carbohydrate, High Fiber Diet on Hyperglycemic Diabetic Men. The American Journal of Clinical Nutrition, 29, 895-899. https://doi.org/10.1093/ajcn/29.8.895

[64] Katan, M.B. (1997) High-Oil Compared with Low-Fat, High-Carbohydrate Diets in the Prevention of Ischemic Heart Disease. The American Journal of Clinical Nutrition, 66, 974S-979S. https://doi.org/10.1093/ajcn/66.4.974S

[65] American Diabetes Association (1993) Nutritional Recommendations and Principles for Individuals with Diabetes Mellitus. Diabetes Care, 16, 22-29.

https://doi.org/10.2337/diacare.16.2.22

[66] Barnard, N.D., Cohen, J., Jenkins, D.J.A., Turner-McGrievy, G., Gloede, L., Jaster, B., Seidl, K., Green, A.A. and Talpers, S. (2006) A Low-Fat Vegan Diet Improves Glycemic Control and Cardiovascular Risk Factors in a Randomized Clinical Trial in Individuals with Type 2 Diabetes. Diabetes Care, 29, 1777-1783.

https://doi.org/10.2337/dc06-0606

[67] Masharani, U., Sherchan, P., Schloetter, M., Stratford, S., Xiao, A., Sebastian, A., Nolte, K.M. and Frassetto, L. (2015) Metabolic and Physiologic Effects from Consuming a Hunter-Gatherer (Paleolithic)-Type Diet in Type 2 Diabetes. European Journal of Clinical Nutrition, 69, 944-948. https://doi.org/10.1038/ejcn.2015.39

[68] Elhayany, A., Lustman, A., Abel, R., Attal-Singer, J. and Vinker, S. (2010) A Low Carbohydrate Mediterranean Diet Improves Cardiovascular Risk Factors and Diabetes Control among Overweight Patients with Type 2 Diabetes Mellitus: A 1-Year Prospective Randomized Intervention Study. Diabetes, Obesity and Metabolism, 12, 204-209. https://doi.org/10.1111/j.1463-1326.2009.01151.x

[69] Evert, A.B., Dennison, M., Gardner, C.D., et al. (2019) Nutrition Therapy for Adults with Diabetes or Prediabetes: A Consensus Report. Diabetes Care, 42, 731-754. https://doi.org/10.2337/dci19-0014

[70] Schwingshackl, L., Chaimani, A., Hoffmann, G., Schwedhelm, C. and Boeing, H. (2018) A Network Meta-Analysis on the Comparative Efficacy of Different Dietary Approaches on Glycaemic Control in Patients with Type 2 Diabetes Mellitus. European Journal of Epidemiology, 33, 157-170. 
https://doi.org/10.1007/s10654-017-0352-x

[71] Meng, Y., Bai, H., Wang, S., Li, Z., Wang, Q. and Chen, L. (2017) Efficacy of Low Carbohydrate Diet for Type 2 Diabetes Mellitus Management: A Systematic Review and Meta-Analysis of Randomized Controlled Trials. Diabetes Research and Clinical Practice, 131, 124-131. https://doi.org/10.1016/j.diabres.2017.07.006

[72] Kirkpatrick, C.F., Bolick, J.P., Kris-Etherton, P.M., et al. (2019) Review of Current Evidence and Clinical Recommendations on the Effects of Low-Carbohydrate and Very-Low-Carbohydrate (Including Ketogenic) Diets for the Management of Body Weight and Other Cardiometabolic Risk Factors: A Scientific Statement from the National Lipid Association Nutrition and Lifestyle Task Force. Journal of Clinical Lipidology, 13, 689-711.e1. https://doi.org/10.1016/j.jacl.2019.08.003

[73] Grotz, V.L., Pi-Sunyer, X., Porte, D., Roberts, A. and Richard, T.J. (2017) A 12-Week Randomized Clinical Trial Investigating the Potential for Sucralose to Affect Glucose Homeostasis. Regulatory Toxicology and Pharmacology, 88, 22-33.

[74] Rivellese, A.A., Giacco, R. and Costabile, G. (2012) Dietary Carbohydrates for Diabetics. Current Atherosclerosis Reports, 14, 563-569.

https://doi.org/10.1007/s11883-012-0278-4

[75] Coulston, A.M., Hollenbeck, C.B., Donner, C.C., et al. (1985) Metabolic Effects of Added Dietary Sucrose in Individuals and Non-Insulin-Dependent Diabetes Mellitus (NIDDM). Metabolism, 34, 962-966. https://doi.org/10.1016/0026-0495(85)90146-5

[76] Gregory, N., McCoy, S. and Kabadi, U.M. (1998) Unchanged Glycemic Responses on Inclusion of Sucrose in Daily Meals in Type 2 Diabetes Mellitus. Diabetes, 37, 1314.

[77] Peterson, D.B., Lambert, J., Gerring, S., Darling, P., Carter, R.D., Jelfs, R. and Mann, J.I. (1986) Sucrose in the Diet of Diabetic Patients-Just Another Carbohydrate? Diabetologia, 29, 216-220. https://doi.org/10.1007/BF00454878

[78] Nathan, D.M., Godine, J.E., Gauthier-Kelley, C., et al. (1984) Ice Cream in the Diet of Insulin-Dependent Diabetic Patients. JAMA, 251, 2825-2827.

https://doi.org/10.1001/jama.1984.03340450041024

[79] Souto, D.L., Dantas, J.R., Dos Santos Oliveira, M.M., Rosado, E.L., Luiz, R.R., Zajdenverg, L. and Rodacki, M. (2018) Does Sucrose Affect the Glucose Variability in Patients with Type 1 Diabetes? A Pilot Crossover Clinical Study. Nutrition, 55-56, 179-184. https://doi.org/10.1016/j.nut.2018.05.009

[80] Schulman, A.R. and Thompson, C.C. (2017) Complications of Bariatric Surgery: What You Can Expect to See in Your GI Practice. American Journal of Gastroenterology, 112, 1640-1655. https://doi.org/10.1038/ajg.2017.241

[81] O’Brien, P.E., Hindle, A., Brennan, L., Skinner, S., Burton, P., Smith, A., Crosthwaite, G. and Brown, W. (2019) Long-Term Outcomes after Bariatric Surgery: A Systematic Review and Meta-Analysis of Weight Loss at 10 or More Years for All Bariatric Procedures and a Single-Centre Review of 20-Year Outcomes after Adjustable Gastric Banding. Obesity Surgery, 29, 3-14.

https://doi.org/10.1007/s11695-018-3525-0

[82] Roth, A.E., Thornley, C.J. and Blackstone, R.P. (2020) Outcomes in Bariatric and Metabolic Surgery: An Updated 5-Year Review. Current Obesity Reports, 9, 380-389. https://doi.org/10.1007/s13679-020-00389-8

[83] Lingvay, I., Sumithran, P., Cohen, R.V. and Roux, C.W. (2021) Obesity Management as a Primary Treatment Goal for Type 2 Diabetes: Time to Reframe the Conversation. The Lancet. https://doi.org/10.1016/S0140-6736(21)01919-X 
[84] Zuti, W.B. and Golding, L.A. (1976) Comparing Diet and Exercise as Weight Reduction Tools. The Physician and Sportsmedicine, 4, 49-53.

[85] Goodyear, L.J. and Kahn, B.B. (1998) Exercise, Glucose Transport, and Insulin Sensitivity. Annual Review of Medicine, 49, 235-261.

https://doi.org/10.1146/annurev.med.49.1.235

[86] Borghouts, L.B. and Keizer, H.A. (2000) Exercise and Insulin Sensitivity: A Review. International Journal of Sports Medicine, 21, 1-12.

https://doi.org/10.1055/s-2000-8847

[87] Kumar, A.S., Maiya, A.G., Shastry, B.A., Vaishali, K., Ravishankar, N., Hazari, A., Gundmi, S. and Jadhav, R. (2019) Exercise and Insulin Resistance in Type 2 Diabetes Mellitus: A Systematic Review and Meta-Analysis. Annals of Physical and Rehabilitation Medicine, 62, 98-103. https://doi.org/10.1016/j.rehab.2018.11.001

[88] Whillier, S. (2020) Exercise and Insulin Resistance. Advances in Experimental Medicine and Biology, 1228, 137-150. https://doi.org/10.1007/978-981-15-1792-1_9

[89] Ayabe, M., Aoki, J., Kumahara, H., Yoshimura, E., Matono, S., Tobina, T., Kiyonaga, A., Anzai, K. and Tanaka, H. (2011) Minute-by-Minute Stepping Rate of Daily Physical Activity in Normal and Overweight/Obese Adults. Obesity Research \& Clinical Practice, 5, e79-e156. https://doi.org/10.1016/j.orcp.2010.12.009

[90] Tudor-Locke, C., Craig, C.L., Aoyagi, Y., Bell, R.C., Croteau, K.A., De Bourdeaudhuij, I., Ewald, B., Gardner, A.W., Hatano, Y., Lutes, L.D., Matsudo, S.M., Ramirez-Marrero, F.A., Rogers, L.Q., Rowe, D.A., Schmidt, M.D., Tully, M.A. and Blair, S.N. (2011) How Many Steps/Day Are Enough? For Older Adults and Special Populations. International Journal of Behavioral Nutrition and Physical Activity, 8, 80. https://doi.org/10.1186/1479-5868-8-80

[91] Tudor-Locke, C., Craig, C.L., Brown, W.J., Clemes, S.A., De Cocker, K., Giles-Corti, B., Hatano, Y., Inoue, S., Matsudo, S.M., Mutrie, N., Oppert, J.M., Rowe, D.A., Schmidt, M.D., Schofield, G.M., Spence, J.C., Teixeira, P.J., Tully, M.A. and Blair, S.N. (2011) How Many Steps/Day Are Enough? For Adults. International Journal of Behavioral Nutrition and Physical Activity, 8, 79. https://doi.org/10.1186/1479-5868-8-79

[92] Tudor-Locke, C. and Rowe, D.A. (2012) Using Cadence to Study Free-Living Ambulatory Behaviour. Sports Medicine, 42, 381-398.

https://doi.org/10.2165/11599170-000000000-00000

[93] Tudor-Locke, C., Brashear, M.M., Katzmarzyk, P.T. and Johnson, W.D. (2012) Peak Stepping Cadence in Free-Living Adults: 2005-2006 NHANES. Journal of Physical Activity and Health, 9, 1125-1129. https://doi.org/10.1123/jpah.9.8.1125

[94] Aguiar, E.J., Gould, Z.R., Ducharme, S.W., Moore, C.C., McCullough, A.K. and Tudor-Locke, C. (2019) Cadence-Based Classification of Minimally Moderate Intensity during Overground Walking in 21- to 40-Year-Old Adults. Journal of Physical Activity and Health, 16, 1092-1097. https://doi.org/10.1123/jpah.2019-0261

[95] Marshall, S.J., Levy, S.S., Tudor-Locke, C.E., Kolkhorst, F.W., Wooten, K.M., Ji, M., Macera, C.A. and Ainsworth, B.E. (2009) Translating Physical Activity Recommendations into a Pedometer-Based Step Goal: 3000 Steps in 30 Minutes. American Journal of Preventive Medicine, 36, 410-415. https://doi.org/10.1016/j.amepre.2009.01.021 